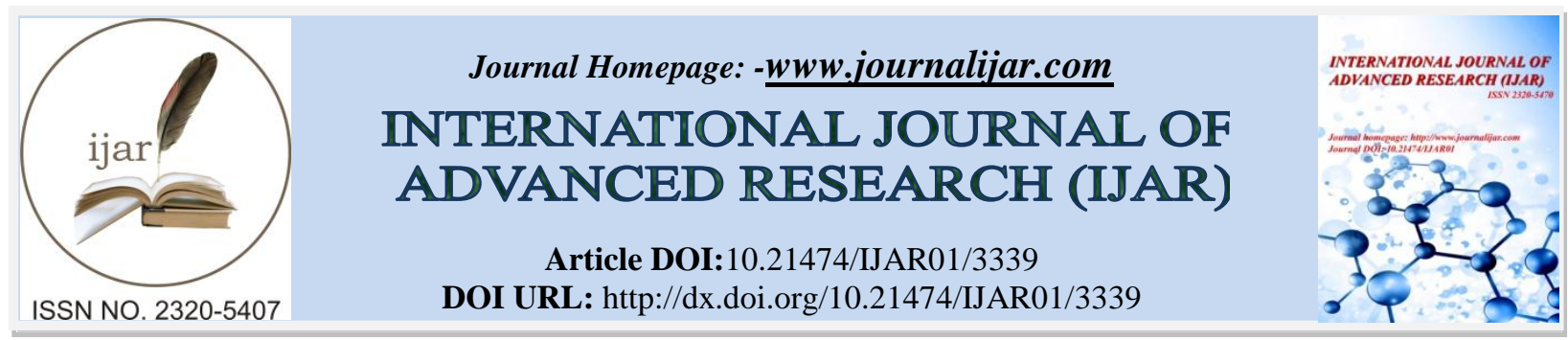

RESEARCH ARTICLE

\title{
PARENTING STRESS ASSOCIATED WITH DIFFERENTLY ABLED CHILDREN...THAT MAY INFLUENCE SEEKING DENTAL CARE?
}

Faraz Ahmed ${ }^{1},{ }^{*}$ Arathi Rao ${ }^{2}$ and Suprabha BS $^{3}$.

1. Post Graduate Student, Paedodontics\& Preventive Dentistry, Manipal College of Dental Sciences, Manipal University, Mangalore.

2. Professor \& Head, Paedodontics\& Preventive Dentistry, Manipal College of Dental Sciences, Manipal University, Mangalore.

3. Professor, Paedodontics\& Preventive Dentistry, Manipal College of Dental Sciences, Manipal University, Mangalore.

\section{Manuscript Info}

Manuscript History

Received: 29 December 2016

Final Accepted: 15 January 2017

Published: February 2017

\begin{abstract}
Parenting a differently abled child is not an easy task. Such parents experience variety of stress related issues. For this difficult task parents especially mothers' require every help and possible encouragement. Parents and siblings should experience variety of extreme adjustments to adapt to the presence of a disabled child. Analysis have shown that families which can cope successfully with a differently abled child are able to mobilize their internal and external means of support to tackle efficiently with the special needs of their child. This review article highlights the parenting stress associated with differently abled children which may indirectly influence their approach towards seeking dental care.
\end{abstract}

Copy Right, IJAR, 2017,. All rights reserved.

\section{Introduction:-}

Parents play an important role in child's life, influencing their social, emotional, and academic development and adjustments. Parents also play an important role in supervising and maintaining their health care needs including oral hygiene and dietary habits. It has been reported that parents with good oral health knowledge can be responsible in sustaining favorable oral health of their children1-3.But the question is - "Is that enough just to educate parents and except them to begin changing their daily oral hygiene routine, especially in parents of disabled children - Are they in a state to provide the necessary health care??

Just educating parents about oral hygiene maintenance may not be adequate. Children who are normal advance from one stage of development to the next and their parents perceive them with satisfaction. When behavior of the child diverge from the ideal standards, family problems may develop 4.

Differently abled child's birth is an unanticipated tense event which disturbs the entire family and will impair family development. Parents go through intense stress which may be emotional, psychological, social etc5.

Attractive, smart, graceful, sophisticated and athletic children are expected by most of the parents. Parents of differently abled child not only grieve for the loss of unfulfilled expectations but frequently encounter colossal

Corresponding Author:-Arathi Rao.

Address:-Professor \& Head, Paedodontics\& Preventive Dentistry, Manipal College of Dental Sciences, Manipal University, Mangalore. 
burden on their emotional and financial assets have excessive stress and reduced level of comfort as compared to the parents of normal children5,6.

Parenting behavior is influenced by many factors and one such aspect is parenting stress. Parenting stress can be described as excess anxiety and tension specifically related to the role of a parent and to parent-child interactions7. Plethora of evidence is there that additional amount of emotional stress is experienced by parents of children with retardation. It is reported that parents of mentally and physically challenged children are more upset, socially secluded and confined in their parental roles in comparison with parents of children with normal behaviour8. Increased levels of stress across all sections in parents of children with developmental disorders have been reported by Beckman9. It is reported that behavioral and developmental disability was linked with excessive parenting stress than medical disorder $\mathbf{1 0 .}$

It is documented that parental stress and adaptation rely upon the kind of disability, the family's coping facilities, conventional and unconventional supports in the society. Parent's previous psychological make up, accessibility and standard of professional assistances, marital interaction, religious perspectives, attitudes, number of members in the family also affects family adaptation. The quantity of assistance the parents obtain from companions, family members and professionals, regulates the self-resolution and intellectual performance of the parents6,11.

\section{Type of stress:-}

The nature of stress and areas of stress in parents of the mentally challenged have been studied extensively12-15.

a. Care stress

b. Social stress - poor social relationships and lack of holidays or free time

c. Emotional stress

d. Financial stress -Families with low income is reported to be correlated with increased stress because of insufficient facilities.

\section{Factors affecting stress:-}

1. Mothers' vs Fathers - The mothers experience higher stress than the fathers when it comes to daily care, emotional and social stress as mothers are usually directly involved in child care. Father's stress is attributed from disturbed behavior and decreased leisure time. Regarding financial stress, there were no differences between the parents15.

2. Siblings - Effect on siblings such as that of adjustment creates stress on both the parents but absence of normal siblings in the family of mentally challenged children does not make significance difference in stress experienced by the parents16.

3. Gender of the child - Gender and age of the child influences the stress in parents. Tangri and Verma17report higher stress in parents of female retarded children. When the child with disability is female, marital stress among parents is also seen and affinity is compromised $\mathbf{1 8 .}$

4. Age - Lower age of the mentally challenged individual is associated with an increase in stress.14,19Lesser the parents age higher is the parental stress, probably due to reduced experience and restrictions involved 20.

5. Severity of retardation: It is observed that parents of severe and profoundly retarded children have higher stress 21 but in Indian scenario parents of mildly retarded group also exhibit higher stress 13.

6. Educational level of parents - Educational level of parents does show clear influence on parental stress and higher stress is reported in educated group, which may be due to the additional social stress involved 22. Prabhu23 found that mental retardation is not considered as a serious problem especially in the agricultural communities, which may due to impaired sense of competence, less restrictions in their lifestyles, etc. Higher stress among educated parents may exist because of increased expectations of their children, higher sense of humiliation, annoyed at incapable of not being able to rehabilitate the state of the child and more limitations on their community and professional actions 24-25. Increased stress was encountered in parents who worked as professionals and managers as compared to parents who were employed as laborers and assistants. Impaired sense of ability, limitations put on other lives, insufficient social assistance and depression can be the reasons 26.

7. Support and resources - The studies reveals that knowledge on the value of informal support by extended family is inconsistent. Parents in joint families have support from grandparental and other family members thus reducing parental stress27. But it has been reported that family support can be a troublesome because of morebehaviorissues or excessive demands. Family adaptation has been encouraged and a decrease stress has been found by the assistance from the spouse and nearby relatives28. Most of the parents in India do not use 
formal resources such as social support groups or family counselling due to the disgracelinked to disability and the harm to the family's prestige and this may further increase the stress.

\section{Burden reported29-32:-}

The kind of burdens reported by family members vary from

a. Difficulties in transportation of thechild to the place of service delivery

b. Management of behavior problems

c. Disruption of their daily routine

d. Economic, physical and social burden.

\section{Parental Coping mechanisms:-}

Trust in God, spirit and self-belief to the external aids such as assistance from family members, relatives, professionals, and Governmental policies are various coping resources33. Parenting stress is found to be reduced by religious coping $\mathbf{3 4 , 3 5}$. It is also intriguing to be aware that music and television has been used by the parents to decrease the stress of handling with the situation.

\section{Conclusion:-}

Stress may also interfere in parent's ability to provide good oral health care. It is therefore necessary not only to educate parents but also to understand, assess and counsel parental stress related issues. Most of the time importance is given only to the difficult areas associated with children with special needs such as soft diet high in carbohydrates, lack of muscle movement and coordination making it difficult to effectively brush the teeth predisposing these children to a higher risk for dental caries and gingival diseaseetc, but the parental stress is totally ignored.36

Formation of dental teams with knowledge, empathy and providing education keeping in mind the associated stress involved, is what parents need. The dental community has to increase its effort for providing full support to parents and these children in the form of continuous encouragement apart from providing oral health education and dental care facilities.

\section{References:-}

1. Petersen PE, Danila I, Samoila A. Oral health behavior, knowledge and attitudes of children, mothers and schoolteachers in Romania in 1993. ActaOdontolScand1995; 53: 363-682.

2. Al-Tamimi S, Petersen PE. Oral health situation of schoolchildren, mothers and teachers in Saudi Arabia. Int Dent J 1998; 48: 180-186.

3. Petersen PE, Esheng Z. Dental caries and oral health behavior situation of children, mothers and teachers in Wohan, Peoples Republic of China. Int Dent J 1998; 48: 210-216.

4. Vijesh, P. V. and Sukurnaram, P. S. Stress among the mothers of children with cerebral palsy attending special schools. Asia Pacific Disab. Rehab. J. 2007; 18(1):76-91.

5. Rangaswamy, K. and Bhavani, K. Impact of disability on the family and needs of families of disabled children, J. Commu. Guid. Res.2008;25(1): 121- 130.

6. Kumar V. Psychological stress and coping strategies of the parents of mentally challenged children..Journal of the Indian Academy of Applied Psychology. 2008; 34 (2): 227-231.

7. Abidin, R. R. Parenting stress index. Psychology Press, Odessa, USA.1995.

8. Mash EJ, Johnston C. Parental perceptions of child behaviour problems, parenting selfesteem, and mother's reported stress in younger and older hyperactive and normal children. Journal of Consulting and Clinical Psychology. 1983; 51: 86-99.

9. Beckman PJ. Comparison of mothers' and fathers' perceptions of the effect of young children with and without disabilities. American Journal of Mental Retardation.1992; 95: 585-595.

10. Gupta VB. Comparison of parenting stress in different developmental disabilities. Journal of Developmental \& Physical Disabilities, 2007; 19: 417-425.

11. Featherstone Helen.A difference in the family. Living with a disabled child, U.S.A:1986; Penguin Books..

12. Seth S. Maternal attitude toward mentally retarded children. In Developmental Psychology. 1979; Parameswaran and Bhogle (Eds), Light and Life Publishers, New Delhi.

13. Prabhu, G.G. The implications of mental handicap to the family: A project report. 1989. Govt. of India, Ministry of social welfare. 
14. Pariante, C.M. \&Carpiniello, B. Family burden in relatives of schizophrenics and of people with mental retardation: A comparative study. European Psychiatry,1996; 11:381-385.

15. Sameroff A, Seifer R, Barocas B, Zax M, Greenspan S. IQ scores of four-year-old children: socioenvironmental risk factors. Pediatrics; 1987; 79: 343-350.

16. Fisman, S., Wolf, L., Ellison, D. \& Freeman, T. A longitudinal study of siblings of children with chronic disabilities. Canadian Journal of Psychiatry, 2000; 45:369-375.

17. Tangri P \&Verma P. (1992). A study of social burden felt by mothers of handicapped children. Journal of Personality and Clinical Studies,1992;8(2): 117-120.

18. Padencheri S, Swamidhas P, Russell S (2011). The role of gender of children with intellectual disability and their parents in marital intimacy in southern India. Journal of Intellectual Disability. 2011; 15: 241-251.

19. Leyser, Y. \&Deckel, G. Perceived stress and adjustment in religious Jewish families with a child who is disabled. The Journal of Psychology, 1990; 125(4): 251-255.

20. Gandotra, V. S. Management problems and practices of home makers with a disabled member in the family. The Indian Journal of Social Work, XLV, 1985; 485-490.

21. Gosch, A. Maternal stress among mothers of children with Williams-Beuren syndrome, Down syndrome and mental retardation of nonsyndromal etiology in comparison to mothers of non disabled children. Zeitschrift fur Kinder- und Jugendpsychiatrie und Psychotherapie, 2001; 29: 285-295.

22. Behari, R. The maternal attitude- Child rearing link for mentally retarded children: A case study. Disabilities and Impairments, 1995;9: 44-51.

23. Prabhu, G. G. Mental Retardation in India - Spring board for action. Federation for the welfare of the mentally retarded, 1978, New Delhi.

24. Lewis O. The culture of poverty. Society, 1998;35 (2): 7-9.

25. Kumar M. Poverty and culture of daily life. Psychology Developing Societies, 2010; 22 (2):331-359.

26. Padencheri S, Swamidhas P, Russell S. The role of gender of children with intellectual disability and their parents in marital intimacy in southern India. Journal of Intellectual Disability, 2011; 15: 241-251

27. Hornby, G. \& Ashworth, T. Grandparent's support for families who have children with disabilities. Journal of Child and Family Studies, 1994; 3: 403-412.

28. Hanson MJ, Hanline MF.Parenting a child with a disability: A longitudinal study of parental stress and adaptation. Journal of Early Intervention, 1990; 14: 234-248.

29. Venkatesan, S. \& Das, A.. K. Reported burden on the family members in receiving / implementing home based training programs for children with mental handicaps. Journalof Psychological Researches, 1994;38, 39-45.

30. Upadhyaya GR, Havalappanavar NB. Stress in parents of the mentally challenged. Jn In Academy Applied Psychology, 2008:34;53-59.

31. Heller T, Hsieh K \&Rowitz L. Maternal and paternal care giving of persons with mental retardation across the lifespan. Family relations: Interdisciplinary journal of applied family studies, 1997;46:407-415.

32. Sequeira, E. M., Rao, M. P., Subbakrishna, D. K. \&Prabhu, G. G. Perceived burden and coping styles of the mothers of mentally handicapped children. NIMHANS Journal,1990;8:63-67.

33. Peshawaria R, Menon DK, Ganguly R, Roy S, Rajan Pillay PRS, Gupta A. A study of facilitators and inhibitors that affect coping in parents of children with mental retardation in India. Asia Pacific Disability Rehabilitation Journal, 1998; 9(1).

34. Bennett T, Deluca DA, Allen RW. Religion and children with disabilities. Journal of Religion and Health, 1995; 34:301-31.

35. Baldacchino D, Draper P. Spiritual coping strategies: a review of the nursing research literature. Journal of Advanced Nursing; 2001; 34:833-841.

36. Wyne AH. Oral Health knowledge in parents of Saudi Cerebral palsy children. Neurosciences. 2007 ; Vol. 12 (4): 306-311. 